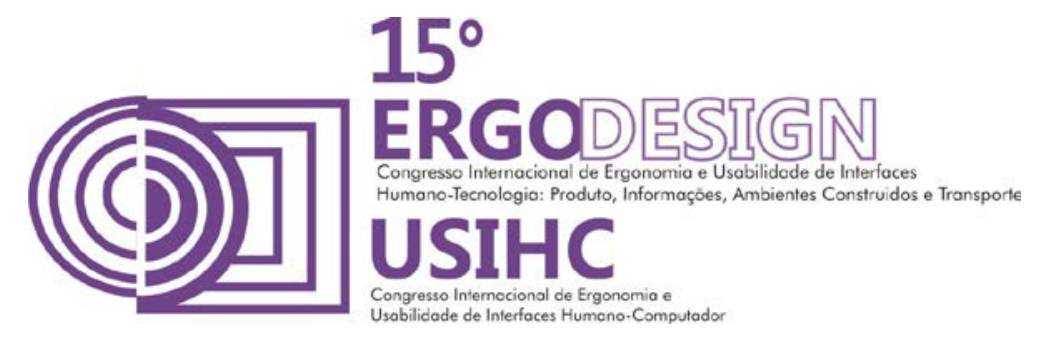

\title{
ESTUDO ERGONÔMICO NA ATIVIDADE DE COLETA DE SANGUE EM UMA INSTITUIÇÃO PÚBLICA DE SAÚDE DO RIO DE JANEIRO
}

\section{ERGONOMIC STUDY IN THE BLOOD COLLECTION ACTIVITY IN A PUBLIC HEALTH INSTITUTION OF RIO DE JANEIRO}

\author{
FREITAS, Katia Butter Leão de \\ Fundação Oswaldo Cruz, Mestre em Ciências \\ e-mail: katia.butter@gmail.com
}

\begin{abstract}
RESUMO
Este estudo busca uma análise das situações de trabalho da Sala de Coleta de Doadores e sua relação com a saúde dos trabalhadores sob a abordagem da Ergonomia e da Ergologia. O método utilizado baseou-se na Análise Ergonômica do Trabalho e as técnicas: observação participante, diário de campo e aplicação de questionário (INSATS-Br). As queixas de dores dos trabalhadores possuem relação com a coleta de sangue, com a organização do trabalho e com o quantitativo de doadores atendidos. Elaborouse um protótipo da mesa de coleta de sangue para transformar a atividade.
\end{abstract}

Palavras-chave: Ergonomia. Ergologia. Saúde do Trabalhador.

\begin{abstract}
The present study attempts an analysis of work situations Room Collection Donors and its relation to the health of workers in the approach of Ergonomics and Ergology. The method used was based on Ergonomic Work Analysis (EWA) and the techniques: participant observation, field diary and questionnaire (INSATS-Br). Complaints of workers pains are related to blood collection, the organization of work and the amount of treated donors. We developed a prototype of blood collection table for transforming activity.
\end{abstract}

Keywords: Ergonomic. Ergology. Occupation Health. 


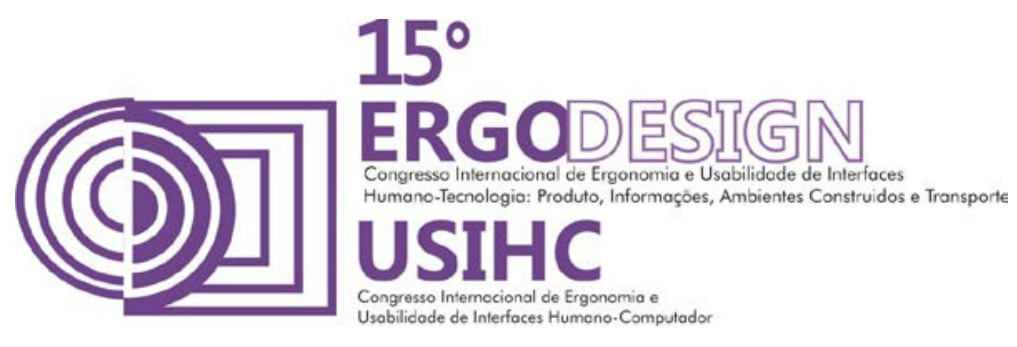

\section{INTRODUÇÃO}

O presente estudo tem como objetivo analisar as situações de trabalho do Salão de Doação de Sangue de uma instituição pública de saúde no Rio de Janeiro e sua relação com a saúde dos trabalhadores.

Certamente, não se contempla aqui todas as variáveis existentes no trabalho intenso de coletar sangue, mas pode apresentar pistas que contribuam para construção de conhecimentos e das práticas necessárias na relação saúde e trabalho do ambiente construído.

O doador de sangue não é um paciente, mas um voluntário que busca um serviço de saúde especializado em Hemoterapia, para realizar a doação de sangue. O trabalho de coleta de sangue é caracterizado por uma demanda de doadores variável, fator que influência na organização do trabalho e na saúde dos trabalhadores. A inexistência de um quantitativo diário fixo de doadores, requer dos gestores a elaboração de estratégias (campanhas de doação, parcerias institucionais, etc.) que contemplem o abastecimento de sangue para suprir as necessidades da instituição.

A coleta de sangue deverá ser realizada de maneira segura e o mais rápido possível, para que $\mathrm{o}$ ato de doar seja motivado a repetição outras vezes. Apenas uma punção deverá ser feita por doação, o que exige habilidade do coletor na punção da veia. Um erro expressa perder uma doação, podendo gerar constrangimentos e sofrimento do trabalhador como também do doador.

A relevância deste estudo se apresenta em consonância com o campo da Saúde do Trabalhador pois se afasta de uma visão restrita, simplista e seguidora de normas prescritas que podem limitar a um agir analítico, crítico e transformador por parte dos trabalhadores; valoriza os trabalhadores da Hemoterapia, pois ao realizarem o trabalho de coleta necessitam de conhecimentos e habilidades singulares e do coletivo de trabalhadores. Também observa-se uma produção científica incipiente, na atividade de coleta de sangue, com as abordagens da Ergonomia e da Ergologia, que trazem a atividade como ponto central.

Neste estudo, os temas saúde e trabalho sob a perspectiva da Ergonomia da Atividade destaca a dimensão coletiva do trabalho, os fenômenos fisiológicos, cognitivos, psíquicos e sociais do qual o trabalhador necessita utilizar para realizar a tarefa (GUÉRIN et al, 2001). Já a perspectiva da Ergologia aponta a existência de uma relação intrínseca entre a atividade, o universo de valores e os saberes envolvidos e construídos nas atividades, pois a atividade de trabalho é sempre mutável, portanto, não se pode padronizá-la (DURRIVE, 2010).

\section{SAÚDE E TRABALHO E AS PERSPECTIVAS ERGONÔMICA E ERGOLÓGICA}

O conceito de saúde passou por transformações, se historicamente era a ausência de uma patologia, atualmente, segundo a Organização Mundial da Saúde - OMS "a saúde é um estado de completo bem-estar físico, mental e social" (DOPPLER, 2007), o que nos faz pensar que a saúde não é estática.

Dejours (2008) apresenta a saúde com a característica dinâmica, num processo construtivo onde o trabalho possui papel fundamental, pois possibilita que o indivíduo participe de uma 


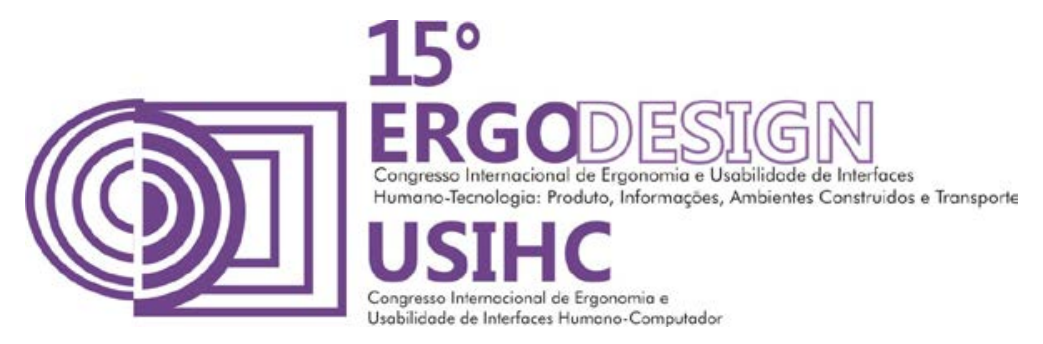

sociedade. Laurell (1981) entende que o trabalho vai além da geração de bens, é uma categoria social, e que para sua análise deve considerar diversas compreensões. Portanto, saúde e trabalho possuem uma relação direta, onde a primeira é construída historicamente na vida de cada sujeito e o trabalho é um dos meios para se alcançá-la, sendo um mediador permanente.

Sob o olhar da Ergonomia, o trabalho é a unidade que provém da atividade, das condições e do resultado da atividade (GUÉRIN et al, 2001). Assim, na compreensão do trabalho considera-se os seus diferentes conceitos que se complementam e colaboram a caracterizar sua complexidade.

Mas o que é trabalhar na perspectiva ergológica? "É gerir defasagens continuamente renovadas" (SCHWARTZ, 2010a), ou seja, trabalhar é gerir as lacunas existentes entre o trabalho prescrito (tarefa) e o trabalho real (atividade). Para Yves Schwartz (2010a) a "Ergologia é a aprendizagem permanente dos debates de normas e de valores que renovam indefinidamente a atividade: é o 'desconforto intelectual'". Portanto, na perspectiva ergológica, a construção dos conhecimentos sobre o trabalho deverá agregar as experiências, os saberes dos trabalhadores produzidos no e pelo trabalho, além de sua confrontação com os saberes produzidos nos variados campos científicos.

O trabalho apresenta duas vertentes: a enigmática e a mecânica, entendendo que ambas são inseparáveis (DURRIVE, 2007). O trabalho é enigmático, pois não temos como conhecê-lo antecipadamente em sua integralidade e porque para realizá-lo necessitamos de um "fazer de outra forma" (SCHWARTZ, 2010b) que depende do pensar e do criar de quem o executa.

Do ponto de vista taylorista, o trabalho é mecânico, pois acreditava-se que as subjetividades dos sujeitos, ao executar o trabalho, poderiam ser deles excluídas e que bastava seguir as instruções técnicas. Mas, contemporaneamente redescobre-se que existe um enigmático alguém no trabalho (SCHWARTZ, 2010c), que traz consigo sentimentos, valores e experiências únicas, contrariando os modelos tayloristas.

Trabalhar vai além da execução, pois o meio é sempre infiel (CANGUILHEM, 1990). Um ambiente de trabalho compreende um conjunto de técnicas, cultura e seres humanos diversos e que não se repetem. Ao se realizar uma tarefa (trabalho prescrito) se torna necessário um conjunto de ações e resultados predefinidos, que serão objetivados pelo trabalhador. O trabalhador apreende e transforma de forma singular as diversas situações de trabalho para cumprir o que lhe é determinado e realiza ajustes/regulações que buscam não prejudicar e/ou interromper a produção do trabalho. Constantemente o trabalhador se confronta com situações diversas que necessitam do conhecimento singular adquirido na trajetória histórica e/ou cultural da equipe ou dele próprio. São algumas variabilidades presentes no trabalho: as panes em equipamentos, dificuldades em instalações diversas, falta ou inadequação de materiais, comunicação, fadiga, diferenças de ritmos, mudanças tecnológicas e organizacionais (BRITO, 2006). Portanto, o trabalho real sempre utiliza o cognitivo e a afetividade do trabalhador, não se limitando a sua execução.

A Ergonomia possibilita mostrar que as prescrições de trabalho não conseguem contemplar as inúmeras situações existentes, mas quando bem definidas as prescrições possibilitam colaborar para o desenvolvimento das atividades. Mas, mesmo assim existem distâncias entre o trabalho real e o trabalho prescrito, que são "fonte produtora de conhecimento em ergonomia" (FERREIRA, 2000). 


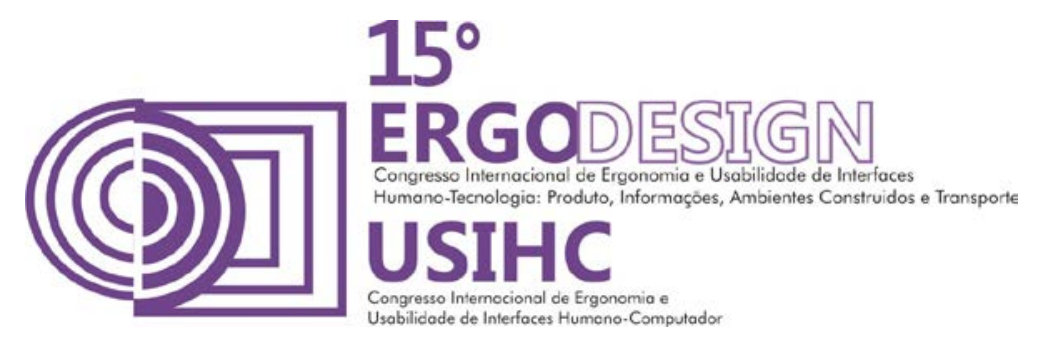

Para Falzon (2007), a atividade não se limita ao comportamento e ao observável, inclui também o inobservável, expressado pela atividade mental, a inteligência, que envolve o comportamento. O caráter dinâmico existente no trabalho solicita ao sujeito a realização de ajustes no que está prescrito para solucionar os problemas e, portanto, a criação e recriação das normas estabelecidas-prescritas.

Vale ressaltar, que muitas vezes, o ato dos trabalhadores de transgredir as normas de trabalho, não deve ser considerado como uma simples arbitrariedade, mas como uma estratégia para atingir melhor os objetivos, conseguir resultados com mais qualidade, assim como também minimizar o uso de ferramentas. Portanto, a violação das normas pode estar vinculada à tentativa de compreender, planejar e resolver problemas, para que o sujeito alcance as exigências do trabalho.

\section{O PROBLEMA}

Este estudo foi motivado por demanda recebida do serviço responsável pela Saúde do Trabalhador, de uma instituição pública de saúde do Rio de Janeiro, que segundo esse, existem diversas queixas osteomusculares e de "estresse"1 dos trabalhadores do Salão de Doação de Sangue. Fez-se necessário, compreender o trabalho visando transformar alguns problemas levantados, após estudo realizado no ambiente, sob a visão da Ergonomia e da Ergologia, o que deu origem a um protótipo de mesa utilizada na atividade de coleta de sangue.

Durante o estudo, antecedente a análise dos resultados do questionário aplicado aos trabalhadores, constatou-se a existência de queixas referente à altura da mesa de coleta associada a realização de movimentos dos membros superiores, que podem contribuir para a existência de dores músculo esqueléticas, no tempo de atendimento ao doador, assim como na qualidade do atendimento. Também destacou-se o ritmo de trabalho que associado ao quantitativo de atendimento de doadores influenciam neste quadro.

\section{METODOLOGIA}

Utilizou-se como recursos metodológicos a observação participante, o diário de campo, a aplicação do questionário (Inquérito Saúde e Trabalho em Serviços-Brasil - INSATS-Br) e registros fotográficos do observado.

Para realização da observação participante, buscou-se norteamento na Análise Ergonômica do Trabalho - AET, com algumas adaptações. O diário de campo foi o instrumento para registrar a "[...] Observação como forma complementar de captação da realidade empírica" (MINAYO, 1993, p.135).

O questionário Inquérito Saúde e Trabalho em Serviços-Brasil - INSATS-Br foi utilizado para analisar os efeitos das condições de trabalho sobre a saúde dos trabalhadores. Tendo como base os inquéritos Surveillance Médicale dês Risques Professionnels - SUMER, Évolutions et Relations em Santé au Travail - EVREST e Saúde, Idade e Trabalho - SIT, todos três buscam:

\footnotetext{
${ }^{1}$ A palavra 'estresse’ utilizada nesta pesquisa, não se refere a uma patologia, mas a um desconforto por parte dos trabalhadores.
} 


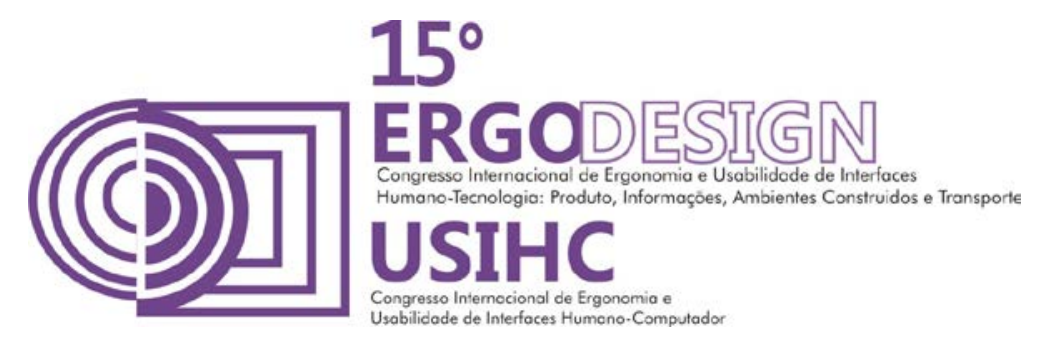

[...] criar condições para que sejam declarados os problemas que consistem fonte de sofrimento, mesmo aqueles que se revelam transitórios e que não se consolidam num quadro de patologia, embora possa ser identificada uma associação com o trabalho (BARROS-DUARTE et al, 2007).

A pesquisa contemplou 21 trabalhadores, que realizam a atividade de coletar sangue. Alguns trabalhadores participaram em todas as etapas e outros não. No preenchimento do questionário INSATS-Br e na validação do design da mesa de coleta de sangue, participaram 12 trabalhadores e no preenchimento do instrumento de validação do protótipo da mesa, participaram 21 trabalhadores. As diferenças de gênero e raça, tempo de serviço e estatura dos participantes desse estudo foram consideradas.

A AET compreendeu 8 (oito) etapas: Análise da Demanda; Análise da tarefa; Primeiro olhar sobre o trabalho; Análise da atividade; Aplicação do questionário INSATS-Br; Validação dos resultados; Elaboração e validação de design gráfico da mesa de coleta de sangue e Elaboração e validação de protótipo da mesa de coleta de sangue.

Todos os participantes, assinaram o Termo de Consentimento Livre e Esclarecido - TCLE, além do projeto ter sido submetido aos Comitês de Ética e Pesquisa correspondentes.

\section{O PROCESSO DE TRANSFORMAÇÃO}

$\mathrm{Na}$ compreensão do processo de trabalho para a transformação, observou-se existir seis macros tarefas no Salão de Doação de Sangue: Etiquetagem, Coleta, Inclusão, Circulante, Repouso do Doador e Chefia.

A primeira etapa da AET - Análise da Demanda contemplou o diálogo com um total de 21 trabalhadores, sendo 5 no exercício de função de chefia e 16 trabalhadores sendo ou não coletores de sangue, objetivando identificar as divergências, exigências das tarefas, os riscos da atividade de coleta de sangue, além de procurar informações relacionadas com os problemas levantados, para a descrição de um quadro básico dos problemas existentes. Buscou-se também conhecer: a história do hospital, o mercado, as sazonalidades, exigências dos usuários, tipos de contratos de trabalho, faixa etária dos trabalhadores, tempo de trabalho, relações sociais, dentre outros aspectos.

A etapa da Análise da tarefa, envolveu conhecer, por meio das observações e explicações dos trabalhadores, o conjunto de prescrições a serem cumpridas pelos trabalhadores. Destacou-se conhecer as ambiências físicas, que na compreensão de Millanvoye (2007) toda tarefa se desenvolve em um contexto que abarca diversos aspectos com potencial nocivo e/ou positivo para saúde dos trabalhadores.

A etapa seguir - $O$ primeiro olhar sobre o trabalho, elaborou-se um pré-diagnóstico para a compreensão sobre o trabalho no Salão de Doação de Sangue, abrindo pistas para possíveis ações futuras e foi validado por meio de diálogo, com 12 trabalhadores, no Salão de Doação de Sangue, em dupla ou/e trio, durante o expediente de trabalho.

Como pré-diagnóstico, apontou-se que a atividade de coleta de sangue leva os trabalhadores coletores de sangue a assumir frequentemente posturas que podem prejudicar a saúde. A altura da mesa de trabalho utilizada na coleta de sangue exige que os trabalhadores realizem 


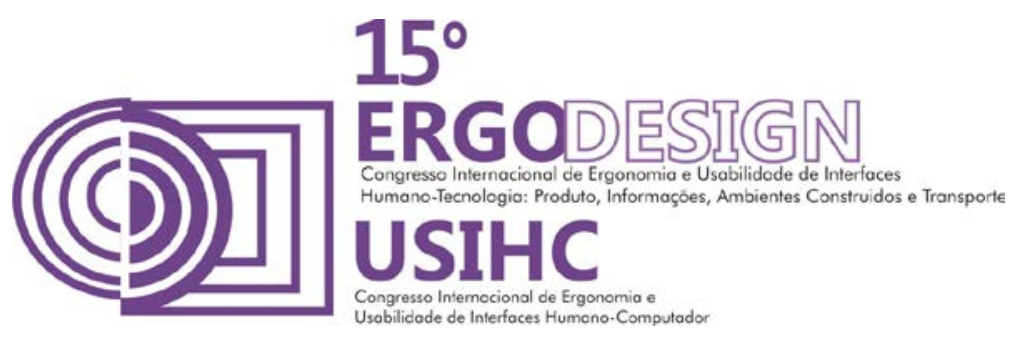

movimentos de extensão e flexão dos membros superiores e flexão de tronco e cabeça, que podem contribuir para o aparecimento de desconforto postural, gerando possíveis queixas de dores osteomusculares; aumentar o tempo de coleta do doador e também reduzir a qualidade de atendimento.

Durante a análise da atividade seis aspectos se destacaram para compreender a atividade de coleta de sangue: os equipamentos/instrumentos; os códigos próprios de comunicação; a variabilidade e a diversidade; os modos operatórios; aspectos posturais do trabalho e os sentidos do trabalho. Buscou-se a compreensão da atividade de coletar sangue; como o trabalhador procede para alcançar os objetivos atribuídos a ele, as regulações e as adaptações. Como ele se relaciona com as regras, normas, máquinas, equipamentos, o fluxo de trabalho, a variação do tempo de atendimento aos doadores, o diálogo existente entre o trabalhador e o doador, a organização do atendimento aos doadores, como os trabalhadores interagem entre eles, os constrangimentos e as variabilidades e outros aspectos. Dividiu-se a atividade de coletar sangue em 10 macros etapas para facilitar a compreensão: preparação do posto de trabalho para iniciar a atividade de coleta de sangue; conferência dos dados do doador; escolha da veia a ser puncionada; realização da antissepsia do local de punção venosa periférica; realização da punção venosa para enchimentos dos tubos de coleta de sangue e da bolsa; controle visual do funcionamento do equipamento homogeneizador e o bem estar do doador; ordenha da bolsa; arrumação da mesa de trabalho; preenchimento dos dados na Ficha de Controle de Doação e informação ao doador sobre os procedimentos após a doação e encaminhamento do mesmo para a Lanchonete.

A aplicação do questionário INSATS-Br contemplou 12 participantes e reafirmou os resultados da etapa metodológica - primeiro olhar sobre o trabalho. Ao analisar as respostas, evidenciou-se os aspectos das exigências físicas: gestos repetitivos, permanência muito tempo sentada, posturas penosas. Já no aspecto das instalações a maioria dos trabalhadores apontou não existir mobiliário (mesas, cadeiras) adequado. Assim como no quadro de problemas de saúde causados ou agravados pelo trabalho, os três problemas que se destacaram foram 0 estresse, as dores musculares crônicas e problemas musculares e das articulações.

A validação dos resultados realizada com os trabalhadores, expressa a participação do coletivo no processo de construção. Para Daniellou e Béguin (2007), os comentários dos trabalhadores enriquecem as observações realizadas e produz conhecimentos no trabalho e sobre o trabalho. Ao se cruzar os dados obtidos pelos métodos e instrumentos, realizou-se análises para verificar as relações existentes nas situações de trabalho com a demanda recebida. Planilhas gráficas ilustraram os resultados que foram apresentados aos trabalhadores do Salão de Doação de Sangue, em pequenos grupos de dois e/ou três, que comentaram, confrontando os vários pontos de vista.

Nesta etapa definiram-se as perspectivas de transformação; acordou-se com os trabalhadores a necessidade de apresentar proposta para transformar a mesa utilizada na atividade de coleta de sangue; além de perguntar aos doze trabalhadores que participaram do INSATS-Br o que faltava na mesa de trabalho para realizar a atividade de coleta de sangue, objetivando buscar aspectos ainda não contemplados. 


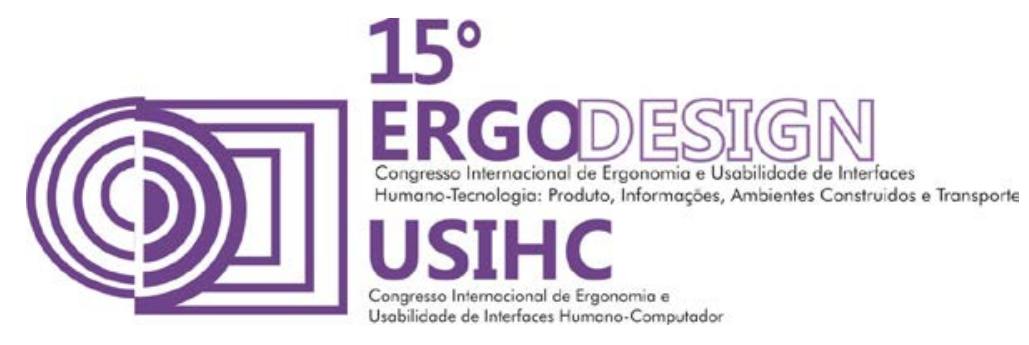

Acordou-se com o coletivo de trabalhadores do campo pesquisado, a realização de um novo design da mesa de coleta, pois abarca um quantitativo maior de trabalhadores e que poderia ser objeto de transformação naquele momento da instituição.

$\mathrm{Na}$ etapa de elaboração e validação de design gráfico da mesa de coleta de sangue, elaborou-se um novo design gráfico da mesa de coleta de sangue, por meio das informações compreendidas e analisadas durante as visitas e após aplicação do questionário INSATS-Br. Este novo design da mesa foi validado com o trabalhador da coordenação de Enfermagem e com o trabalhador da chefia do Setor do Salão de Doação de Sangue e após aprovado, também validado individualmente por 12 trabalhadores coletores, objetivando buscar elementos ainda não contemplados. Do total dos 14 participantes, 11 destacaram que a altura deve ser mais baixa; 9 sugeriram a existência de gaveta para guarda de materiais; 8 apontaram local para se colocar as caixas de descarte dos resíduos e 7 pontuaram a importância de ter mais espaço na mesa. O resultado reforçou a necessidade de transformar a mesa de trabalho.

Após validação, o design foi modificado, contemplando os requisitos dos trabalhadores e considerando-os a todo tempo sujeitos participantes na concepção da mesa e na transformação da atividade de trabalho.

Na elaboração e validação de protótipo da mesa de coleta de sangue, entregou-se um protótipo da nova mesa, e durante cinco dias, o referido mobiliário foi validado com 21 trabalhadores, individualmente, no posto de trabalho. Mais uma vez, solicitou-se aos trabalhadores que apontassem o que poderia melhorar na mesa de coleta para contemplar a atividade de coleta de sangue. A maioria apontou a necessidade de ter apoio para se colocar a seladora. Realizou-se as modificações no protótipo, elaborou-se o design final da mesa e foram compartilhados os resultados com 21 trabalhadores, individualmente e/ou em pequenos grupos (dois e três), no Salão de Doador de Sangue, durante o horário de trabalho.

Aplicou-se um instrumento de validação para compilar as sugestões dos trabalhadores, apresentou legenda de uma escala numérica onde: o número 1 para muito ruim; 2 para ruim; 3 para médio; 4 para bom e 5 para muito bom. Também apresentou espaço para considerações. Analisou-se neste instrumento os mesmos aspectos apontados durante a validação do design da mesa descritos anteriormente, acrescido de cor preferida e local para colocar suporte do equipamento seladora.

Após tabulação e análise do instrumento de validação, elaborou-se o design final da mesa e foram compartilhados os resultados com 21 trabalhadores, no Salão de Doador de Sangue, durante o trabalho.

O protótipo da mesa elaborado possui relação direta com o trabalho no que tange aos aspectos de ritmo, organização, postura e visão do ambiente. Segundo relato de trabalhador do Salão de Doação de Sangue, "Ela é uma concretização dos desejos de todos". Vale ressaltar que a mesa atual também possui design inadequado para os futuros homogeneizadores já solicitados.

Validado o design, com os mesmos 12 trabalhadores que responderam o questionário INSATS$\mathrm{BR}$, elaborou-se o protótipo da mesa e também realizou-se a validação deste. O protótipo apresentado, foi projetado para o novo modelo do homogeneizador, fornecido pelos chefes da coordenação de enfermagem e do setor. Por isso, as prateleiras existentes onde se apoiam os homogeneizadores no momento deste estudo, são provisórias e estão no local onde ficarão as 


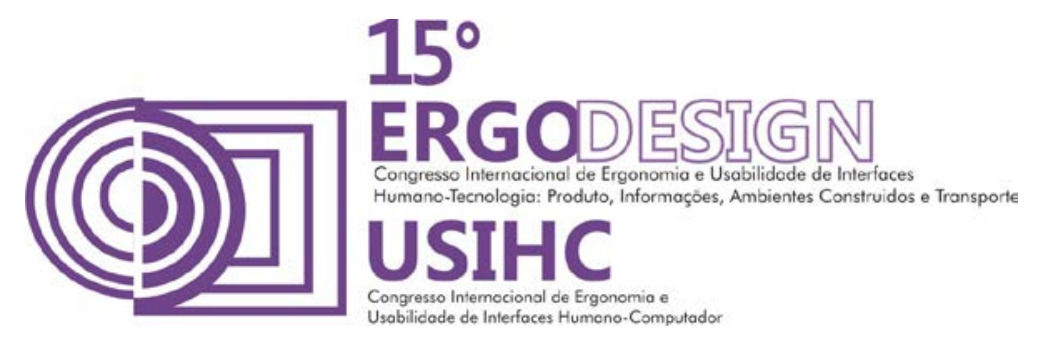

caixas para descarte do material utilizado na atividade de coleta de sangue. Como ainda não s tinha chegado os novos equipamentos, não foi possível utilizá-los na validação.

Os resultados do instrumento de validação do protótipo da mesa com 21 trabalhadores, representa $70 \%$ do total de trabalhadores (30) presentes no Salão de Coleta, durante o período deste estudo. Os aspectos design e área útil, em torno de $50 \%$, foram qualificados como bom e muito bom. A maioria dos outros aspectos ultrapassa $80 \%$ na qualificação de bom e muito bom.

Compreende-se que dialogar coletivamente, é potencializar transformações e dar movimento aos conhecimentos e diferentes olhares. Buscou-se dialogar entre o conhecimento técnicocientífico (saberes constituídos) e o da experiência (saberes investidos).

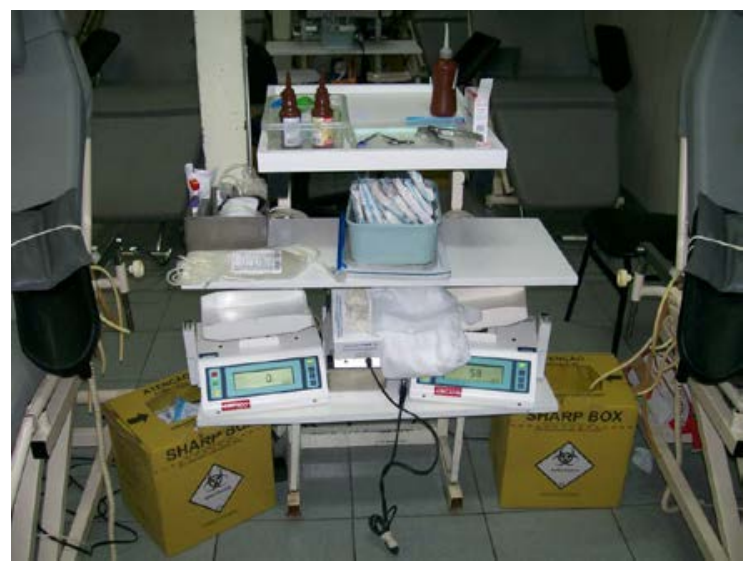

Figura1: Mesa de coleta existente

Fonte: Da autora
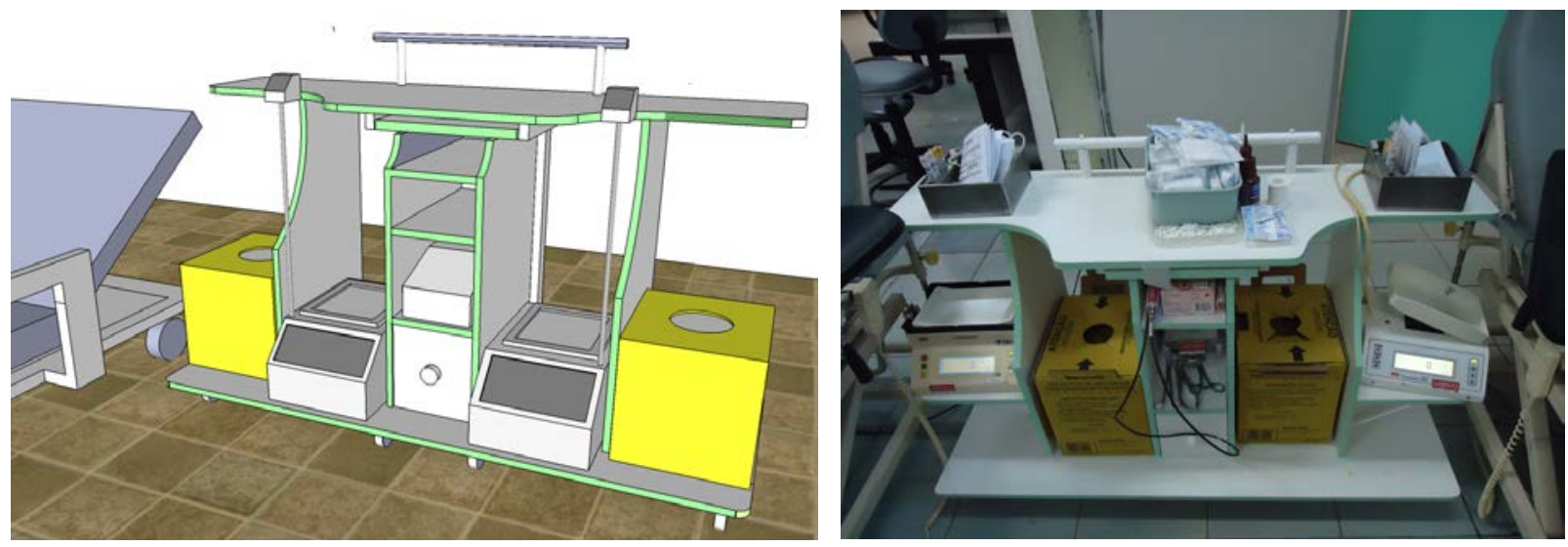

Figuras 2 e 3: Design gráfico e protótipo da nova mesa de coleta de sangue com os homogeneizadores atuais.

Fonte: Da autora 


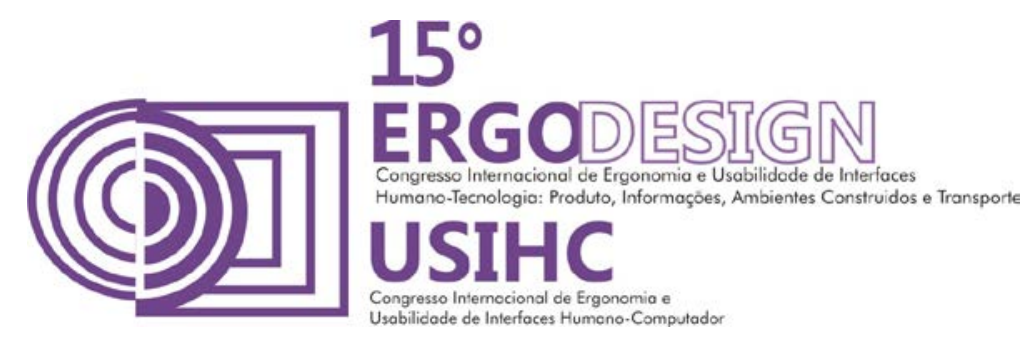

As características do protótipo da nova mesa de coleta de sangue construídas coletivamente, compilados neste estudo são: ser na cor escolhida pela maioria dos trabalhadores, pois a cor é um elemento humanizador que proporciona maior acolhimento dos usuários e beleza; ser revestida em fórmica, para melhor higienização e cumprimento de normas da ANVISA; ter local para as caixas de descarte, deixando de ser um item de não conformidade apontado pela ANVISA; possibilitar o acesso a caixa de descarte dos materiais pérfurocortantes, atenuando as posturas com curvatura da coluna vertebral do trabalhador; ter puxador para facilitar a pega na locomoção desta durante a higienização do piso; possuir rodas de silicone e com travas, para reduzir o impacto nos equipamentos eletrônicos quando for necessário locomover a mesa e mantê-la fixa para realizar a atividade de coleta; ter um design que permita aos trabalhadores uma visão da dinâmica do salão de coleta; apresentar pontas arredondadas nos vértices da estrutura, minimizando possíveis riscos de acidentes; possuir prateleira móvel para preenchimento de dados de controle da doação; ter gaveta para acondicionar materiais utilizados diariamente; otimizar a área de alcance dos trabalhadores.; ser mais baixa que a mesa anterior, reduzindo a elevação dos membros superiores e ter local apropriado para a seladora.

\section{CONSIDERAÇÕES FINAIS}

Conclui-se que não se pode dissociar a saúde do trabalho. O trabalhador sempre está criando e recriando para contemplar as prescrições e exigências da organização do trabalho.

As queixas dos trabalhadores referentes ao estresse, as dores musculares crônicas e os problemas musculares e das articulações na percepção dos trabalhadores possuem relação com a atividade de coletar sangue, com a organização do trabalho e com a quantidade de doadores atendidos.

Embora os trabalhadores tenham sido coautores do conhecimento produzido, a utilização da Antropometria seria necessária para que a mesa de coleta de sangue possuísse uma maior adequação e realização do trabalho de forma segura e saudável. De acordo com Moraes e Quaresma (2005) é recomendável a realização de estudo antropométrico para projetar produtos e estações de trabalho ergonomicamente corretos, pois a utilização de dados antropométricos previne erros relacionados ao dimensionamento.

O presente estudo não possuiu a intenção de solucionar todas as dificuldades dos trabalhadores que realizam o enigmático e intenso trabalho que compreende a atividade de coletar sangue. Mas, acredita-se que proporcionou um espaço de diálogo, escuta e circulação de saberes, fundamental na compreensão e transformação da atividade de trabalho e na construção da saúde do trabalhador.

\section{REFERENCIAS BIBLIOGRAFICAS}

- BARROS-DUARTE, C.; CUNHA, L. \& LACOMBLEZ, M. INSAT: uma proposta metodológica para análise dos efeitos das condições de trabalho sobre a saúde. Laboreal 3, (2), p.54-62, 2007. 


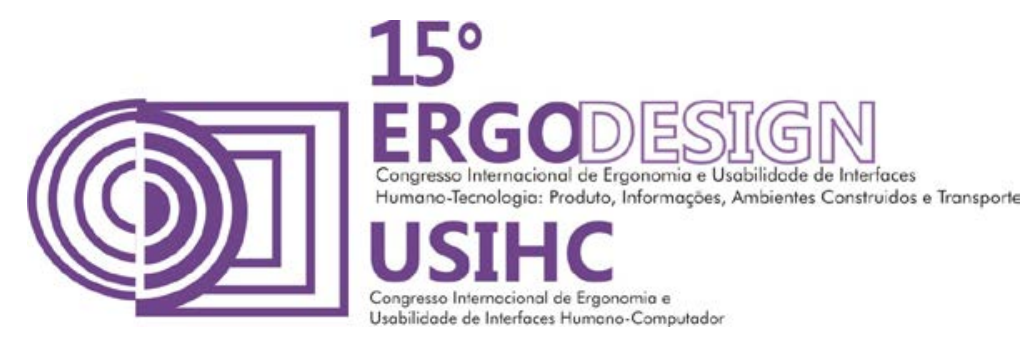

- BRITO, Jussara. Trabalho Prescrito. In: Escola Politécnica de Saúde Joaquim Venâncio. Observatório dos Técnicos em Saúde (org.). Dicionário da Educação Profissional em Saúde, p. 282-287. Rio de Janeiro: Fiocruz, 2006.

- CANGUILHEM, G. O Normal e o patológico. São Paulo: Forense Universitária, 1990.

- DANIELLOU, François e BÉGUIN, Pascal. Metodologia da Ação Ergonômica: abordagem do trabalho real. In: Ergonomia. Pierre Falzon editor, tradução Giliane M.J. et al, revisão técnicocientífica: Laerte Idal Sznelwar, Fausto Leopoldo Mascia, Leila Nandin Zidam; revisão bibliográfica: Vera Lúcia Duarte; coordenação da tradução: Laerte Idal Sznelwar. Editora Blücher Ltda, 2007.

- DEJOURS, Christophe. Da psicopatologia à psicodinâmica do trabalho. Tradução de Franck Soudant. $2^{\mathrm{a}}$ ed. Selma Lancman e Laerte Idal Sznelwar (orgs.). Rio de Janeiro: Ed. Fiocruz, Brasília: Paralelo 15, 2008.

- DOPPLER, Françoise. Trabalho e saúde. In: Ergonomia. Pierre Falzon editor, tradução Giliane M.J. et al, revisão técnico-científica: Laerte Idal Sznelwar, Fausto Leopoldo Mascia, Leila Nandin Zidam; revisão bibliográfica: Vera Lúcia Duarte; coordenação da tradução: Laerte Idal Sznelwar. Editora Blücher Ltda, 2007.

- DURRIVE, L. O formador ergológico ou "ergoformador": uma introdução à ergoformação. In: Trabalho e Ergologia: conversas sobre a atividade humana. Org. de Yves Schwartz e Louis Durrive. trad. Jussara Brito e Milton Athayde et al. Niterói, p.297-309, 2010.

- FALZON, Pierre. Natureza, objetivos e conhecimentos da ergonomia. Elementos de uma análise cognitiva da prática. In: Ergonomia. Pierre Falzon editor, tradução Giliane M.J. et al, revisão técnico-científica: Laerte Idal Sznelwar, Fausto Leopoldo Mascia, Leila Nandin Zidam; revisão bibliográfica: Vera Lúcia Duarte; coordenação da tradução: Laerte Idal Sznelwar. Editora Blücher Ltda, 2007.

- FERREIRA, Mario César. Atividade, categoria central na conceituação de trabalho em ergonomia. Revista Alethéia, Canoas.RS, v.1, n.11, p.71-82, 2000.

- GUÉRIN, F; LAVILLE, A; DANIELLOU, F; DURRAFOURG, J. e KERGUELEN,A. Compreender o trabalho para transformá-lo: a prática da ergonomia. Trad. Giliane M.J.Ingratta e Marcos Maffei. Editora Blücher Ltda, 2001.

- LAUREL, Asa Christina. Processo de Trabalho e Saúde. Revista Saúde em Debate, nº 38. Rio de Janeiro: Ed. Muro, 1981.

- MILLANVOYE, Michel. As ambiências físicas no posto de trabalho. In: Ergonomia. Pierre Falzon editor, tradução Giliane M.J. et al, revisão técnico-científica: Laerte Idal Sznelwar, Fausto Leopoldo Mascia, Leila Nandin Zidam; revisão bibliográfica: Vera Lúcia Duarte; coordenação da tradução: Laerte Idal Sznelwar. Editora Blücher Ltda, p. 73-95, 2007.

- MINAYO, M.C. de S. O Desafio do Conhecimento: Pesquisa qualitativa em saúde. 2 ed. São Paulo: Hucitec, 1993.

- MOREAS Anamaria de; Quaresma, Manuela. O Projeto de Produtos e Estações de Trabalho Ergonômicos Utilizando Dados Antropométricos e Evitando erros de Dimensionamento. In: 


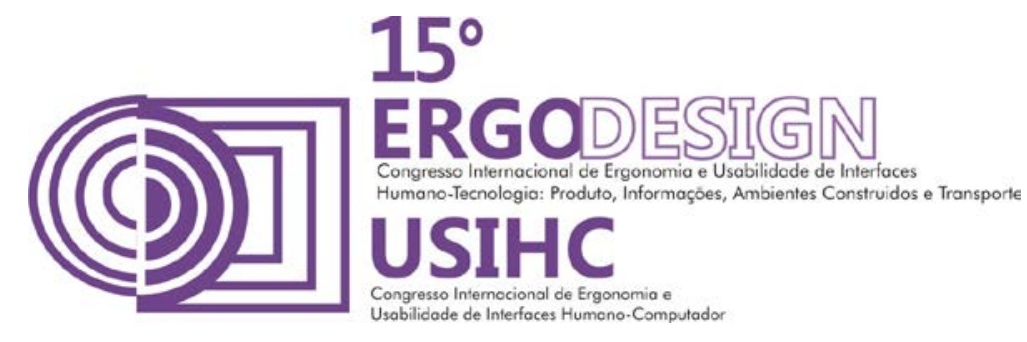

Ergodesign de Produto: Agradabilidade, Usabilidade, Segurança e Antropometria. Anamaria de Moraes (org.). Rio de Janeiro: iUsEr, 2005.

- SCHWARTZ, Yves. O trabalho e o ponto de vista da atividade. In: Trabalho e Ergologia: conversas sobre a atividade humana. Schwartz \& Durrive (orgs.), p. 47-82, Niterói: Eduff, 2010a.

- SCHWARTZ, Yves. O Trabalho e Ergologia. In: Trabalho e Ergologia: conversas sobre a atividade humana. Yves Schwartz; Louis Durrive (orgs.) Trad. Jussara Brito; Milton Athayde et al. p. 25-46, Niterói: Eduff, 2010b.

- SCHWARTZ, Yves. Trabalho e uso de si. In: Trabalho e Ergologia: conversas sobre a atividade humana. Schwartz \& Durrive (orgs.), p. 191-206, Niterói: Eduff, 2010c. 